\title{
Role of Customized Bus Services in the Transportation System: Insight from Actual Performance
}

\author{
Jiangbo Wang $\left(\mathbb{D},{ }^{1}\right.$ Toshiyuki Yamamoto $\mathbb{D}^{2},{ }^{2}$ and Kai Liu $\mathbb{D}^{3}$ \\ ${ }^{1}$ Department of Civil Engineering, Nagoya University, Nagoya, Japan \\ ${ }^{2}$ Institute of Materials and Systems for Sustainability, Nagoya University, Nagoya, Japan \\ ${ }^{3}$ School of Transportation and Logistics, Dalian University of Technology, Dalian, China \\ Correspondence should be addressed to Jiangbo Wang; wangjiangbo@mail.dlut.edu.cn
}

Received 25 March 2019; Revised 18 June 2019; Accepted 9 July 2019; Published 22 August 2019

Academic Editor: Luigi Dell'Olio

Copyright (C) 2019 Jiangbo Wang et al. This is an open access article distributed under the Creative Commons Attribution License, which permits unrestricted use, distribution, and reproduction in any medium, provided the original work is properly cited.

\begin{abstract}
After attaining great prevalence from the end of 2013, customized bus (CB) transit services have experienced a huge decline in China. The feasibility of this new bus sharing system is thus being questioned. Therefore, it is imperative to investigate the actual role of $\mathrm{CB}$ services in the overall transportation system based on successful cases, as the role of the CB service determines its primary service object, system construction, marketing orientation, and even government function. To examine the role of $\mathrm{CB}$ services, this study investigates the practical performance, advantages, and spatial and temporal coverage of a successful CB system based on practical subscription data for more than two years. The results illustrate that the CB service is an eclectic choice that can balance service quality and cost between traveling by traditional public transportation (PT) and private cars/taxis. Even though the travel cost increased to a limited extent, the CB service significantly improved the travel experience in terms of the travel time, travel speed, number of stations, and difference arrival time compared to PT services. The multinomial logit model and regression models demonstrate a significant positive relationship between the relative advantage and amount of demand for the CB services. Furthermore, the CB service primarily serves trips generated during the peak traffic hours of the city and supplements traditional PT service in areas with poor coverage levels.
\end{abstract}

\section{Introduction}

With the rapid urbanization and motorization in developing countries in recent decades, the population of urban areas has increased dramatically, as has the number of vehicles in use. In China, vehicle ownership increased to 310 million vehicles owned by the end of 2017 according to data reported by The Ministry of Public Security of the People's Republic of China [1]. The resulting increasing travel demand in urban areas has led to severe traffic congestion and traffic-related fatalities and injuries owing to the limited network capacity [2]. The continually increasing number of vehicles on the roads will also have a significant impact on greenhouse gas emissions and climate change [3]. For this reason, governments have prioritized the use of PT [4]. Developing an advanced, appealing PT system appears to be the best option (or, perhaps, the only real solution) to tackle the above issues and is in line with policies introduced by governments to restrict the use of private cars based on the number of license plates, including implementing a license plate lottery system for vehicle purchasing, imposing road tolls, raising parking fees, and promoting implementation of electrical buses. These policies were developed to encourage more drivers to use PT system, reduce traffic congestion and vehicle exhaust emissions, and further develop the PT system to promote sustainable transportation system [5-8]. Diversifying PT services is also a way to increase the competitiveness of PT to cater for the diverse travel demand of users.

After decades of development in information and communications technology, a new demand-driven user-oriented PT service, i.e., customized bus (CB), has gained popularity in many large and medium-sized cities in China since its launch in Qingdao in August 2013. Unlike conventional PT services, users can subscribe to $\mathrm{CB}$ services on the telephone, computer, smartphone, or similar devices. The $\mathrm{CB}$ service is popular with citizens because of its simplicity, 
convenience, comfort, and customized features. Despite the prevalence of $\mathrm{CB}$ services, there has been a drastic decline in the number of $\mathrm{CB}$ service users in many cities, such as Guangzhou, Hangzhou, Nanjing, Xiamen, and Harbin. Numerous launched routes have been canceled and many users have unsubscribed from the service and returned to their previous modes of transportation.

Blindly following the development of CB systems before having perfect clarity regarding their role in the overall transportation realm has led to a huge waste of resources in cities that have experienced a drastic decline in customers. In particular, the role of the $\mathrm{CB}$ service will determine its primary service object, system construction, marketing orientation, and even government function. On the other hand, it is difficult for consumers to understand the performance of a CB service before a trial, as there are always some discrepancies between the business advertisements and actual performance.

However, previous studies have mainly focused on creative methods of demand mining, developing routes and network designs, and operation optimization algorithms. There is no consensus on the role of $\mathrm{CB}$ services in modern transportation systems. Thus, it is imperative to investigate their practical performance, advantages, and spatial and temporal coverage, not only for improvement of the system, but also to provide prospective users an insight into traveling via $\mathrm{CB}$ services. Thus, this study covers the lack by a comprehensive analysis of a successful CB system based on practical subscription data for more than two years.

The remainder of this paper is organized as follows: Section 2 focuses on a review of studies relevant to this work, particularly those evaluating the actual performance of public transit systems; an introduction to the study area, selection of metrics, and data collection method is described in detail in Section 3; Section 4 presents the analysis results and discussion of the role of the CB systems; finally, the conclusions drawn from the key findings of this study are presented in Section 5.

\section{Literature Review}

CB transit is a personalized subscription transit service based on aggregating demand with the analogous travel requirements. The origins and destinations of users in the same vehicle are distributed within a limited bundled area over similar departure and arrival times. The basic concept of the $\mathrm{CB}$ service was derived from carpooling services, which began in Zurich in 1948 and operated until 1998 $[9,10]$. The earliest studies concerning the implementation of carpooling into PT systems were conducted in the 1970s $[11,12]$. Henceforth, a number of subscription operations launched across the United States $[13,14]$ to compensate in areas with poor or nonexistent PT services, known as dial-aride.

After decades of development in information and communications technology, a more advanced personalized public transit service occurred in Qingdao, China, in August 2013, which was highly praised by the public. Since then, CB services have become as widespread across China as bamboo shoots after a spring rain. CB systems hold the promise of alleviating urban traffic congestion, particularly under extremely tight road capacity constraints during peak hours. Unlike conventional PT services, CB services are aimed at providing point-to-point transit service for travelers. In particular, CB services are committed to a higher quality level of service than traditional PT service, including guaranteed seats, zero interchange or transfer, short wait times, and greater ride comfort [15]. It was prognosticated many years ago that there was a potential market for demand-oriented and user-driven transit services [16,17].

There have been a wide range of studies focusing on demand identification $[18,19]$, service design and operation optimization [20-23], and performance evaluations [24] of demand-responsive transit systems. Nevertheless, the transit systems analyzed in the above studies primarily provide services for elderly and disabled people. The role of these systems is to complement and supplement normal transit services. The primary service object, orientation, system construction, and operation differ between these demandresponsive systems and $\mathrm{CB}$ systems.

Although CB systems have been developed for several years, there is still no consensus on the role of $\mathrm{CB}$ services in modern transportation systems. Thus, it is imperative to investigate their practical performance, advantages, and spatial and temporal coverage to not only provide experience for system improvement, but also to provide prospective users insight into traveling via a $\mathrm{CB}$ service.

Even though there have been few studies focused on these issues, it is worthwhile to perform an extensive review of the key studies pertaining to performance evaluation and factor selection for similar transit systems. Kirby and Bhatt [14] analyzed ten subscription bus services and identified the following characteristics as key to their success: (1) increased focus on long-distance trips, (2) a dedicated organizational body, (3) convenient sources of buses and drivers, (4) high service reliability, (5) high priority of regulatory requirements, (6) continual adjustment, and (7) satisfactory personalized features. Davison et al. [25] explored demandresponsive transit systems in Great Britain to determine the factors affecting the competitiveness of the systems and their underlying reasons. They highlighted the importance of providing access and geographical coverage, which were also emphasized by Sun et al. [26], and the effect of the number of seats and vehicles was quantified. Based on attributes in terms of economic viability, service provisions, and technical performance, Mageean and Nelson [27] evaluated a set of demand-responsive transportation technologies and operations at urban and rural sites across Europe. Zou et al. [28] established an assessment index system and infrastructure construction, social benefit, and government function were included. Most of these metrics concluded in the literature are from a macropoint of view and therefore provide an overview of performance evaluation of the CB systems.

From a more specific way, a series of factors were quantified to evaluate the performance of the PT system. Based on an analysis of the operation of the PT system in Beijing, China, Li et al. [29] indicated that average running time and service reliability are the key factors influencing 


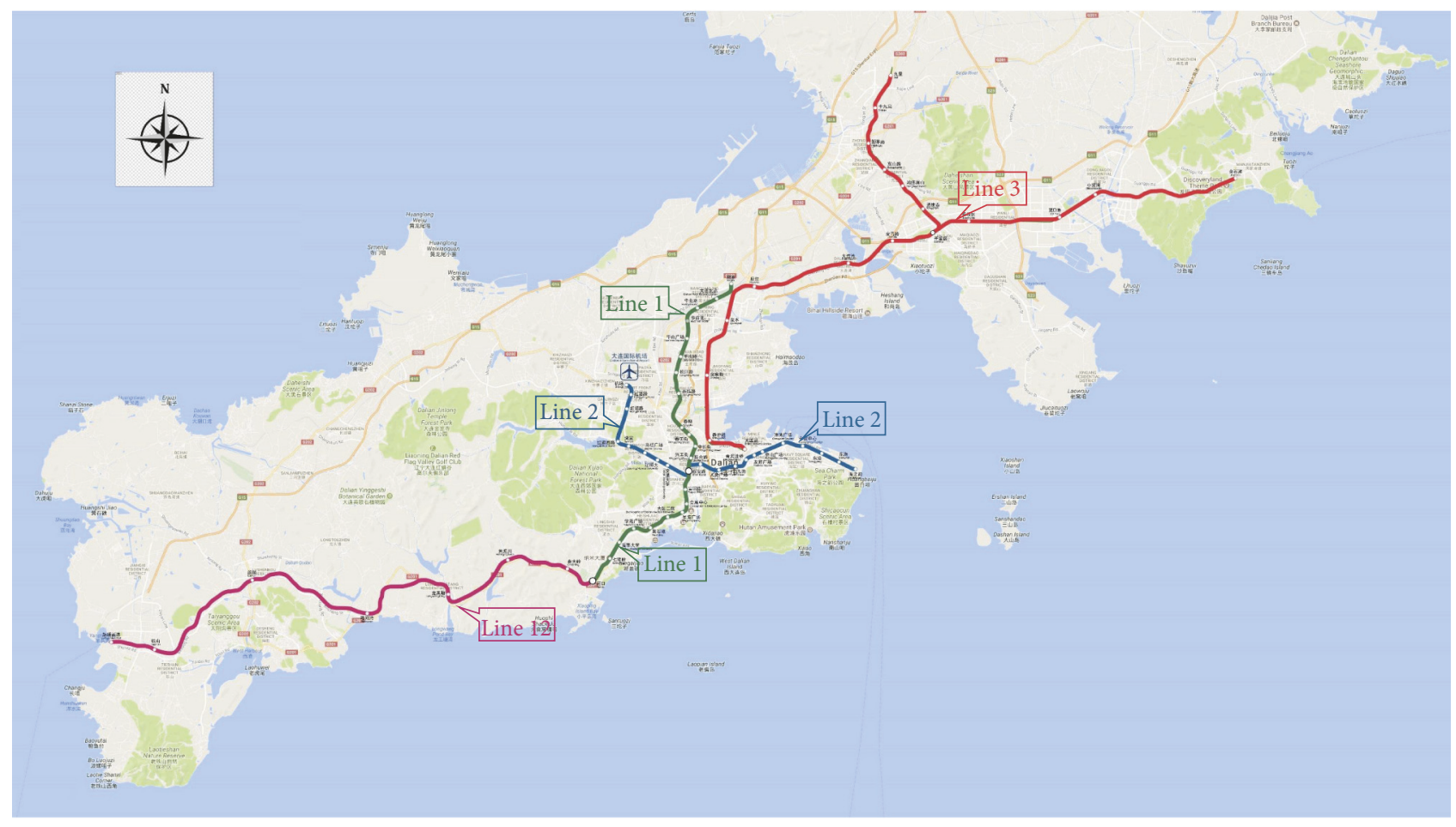

FIGURE 1: Distribution of the railway transportation in Dalian.

the performance. Similarly, Redman et al. [30] also highlighted the service reliability as an important factor for attracting car users, and it significantly affected individual perceptions, motivations, and contexts. de Oña et al. [31] classified the influences of service quality into two underlying dimensions: transport service and comfort and convenience factors. Dell'Olio et al. [32] found that the wait times, cleanliness, and comfort are valuable attributes for users of PT systems. Liu et al. [33] compared the performance of CB with private car and PT in Auckland and Paris, using a proposed simulation framework. Difference arrival time, travel time, travel cost, and fuel consumption were calculated to investigate the difference between the travel modes, their viability, and competitiveness based on 100 randomly generated demands for each city. The attributes relating to route and service characteristics, reliability, comfort and cleanliness, fare, information, safety and security, personnel and customer services, and environmental protection were investigated by Eboli and Mazzulla [34] to measure the performance of PT systems. They also pointed out that a more objective measurement of the metrics can be a useful solution for obtaining a more comprehensive service quality measurement.

\section{Study Area and Data Collection}

3.1. Study Area. The study area for this investigation is Dalian, which is a coastal city located in Northeast China. Dalian is a major city in Liaoning Province, China, and plays a leading role in the economic development of the province. The population of Dalian is more than 6.69 million according to the results of the 6th National Population Census conducted in 2010 [35]. At the end of 2016, it was reported that the total car ownership in Dalian had reached 1.37 million vehicles [36]. The road network and PT system in Dalian City serve millions of trips per day, which leads to severe traffic congestion during peak hours.

There are several different PT modes in Dalian, including subways, rapid railways, and buses. The distribution of railway transportation in the city is shown in Figure 1. Two subway lines (Line No. 1 and Line No. 2) primarily connect the functional areas of the city center, whereas the other rapid railway lines (Line No. 3 and Line No. 12) mainly provide longer-distance travel services for residents.

The first CB route in Dalian began operation in March 2014 in areas city centers located. More CB routes subsequently became available for subscription, and a few private companies collaborated with the government to provide more customized routes to citizens.

The $\mathrm{CB}$ system works as follows. First, prospective $\mathrm{CB}$ users are required to register on a website or online platform and submit a travel request that includes the travel origin-destination (O-D), departure time, and desired arrival time [15]. Upon receiving the travel requests, the $\mathrm{CB}$ service operators design preliminary $\mathrm{CB}$ routes based on the potential demand, and these routes are then uploaded onto the website or online platform to recruit additional users. After negotiating with the users regarding pick-up/dropoff times and pick-up/drop-off stations and optimizing the planned routes to reduce passenger travel time and the operation cost for the $\mathrm{CB}$ service provider, a number of highly occupied CB routes are scheduled, while the rest are canceled. 


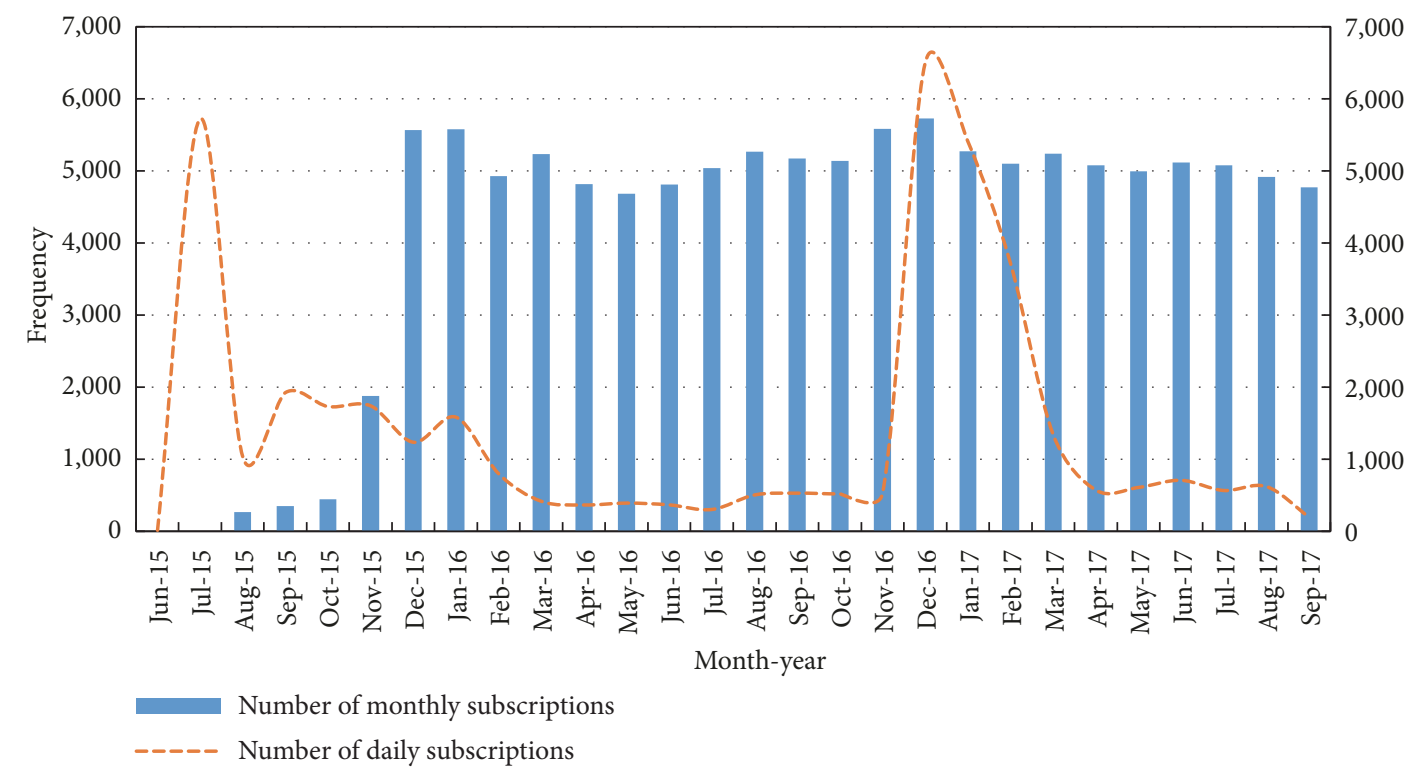

FIGURE 2: Distribution of the number of daily and monthly subscriptions during the study period (June 2015 to September 2017).

To purchase a seat, users can either choose to subscribe to a monthly service (for one-way/round-trip regular routes on weekdays during the month) or daily service (for oneway/round-trip regular routes on a specific day) using convenient smartphone applications. The passengers are required to arrive at the appointed station by the appointed boarding time and show an electric ticket when boarding the bus.

In this study, actual subscription data for the CB system in Dalian was provided by the enterprise, which plays a vital role in initiating and operating CB services in Dalian. The more than two years of subscription data includes the O-D coordinates for each user and all stations for each route in operation.

The number of subscriptions during this period is illustrated in Figure 2. The daily subscription attracted more passengers at the beginning of the service and fluctuated significantly. In contrast, the monthly subscriptions were more stable. Overall, $69 \%$ of the users are female, while only $29 \%$ are male. The remaining $2 \%$ did not provide their gender information because of privacy concerns.

3.2. Performance Data. It is imperative to investigate the practical performance and characteristics of the $\mathrm{CB}$ service not only for improvement of the service, but also to provide prospective users insight into $\mathrm{CB}$ travels. In order to learn a lesson from a CB system that has been operating successfully for more than three years, its practical performance in the transportation realm is investigated and compared to other available modes, including PT, bicycles, taxis, and private cars.

3.2.1. Route and Service Characteristics. The route and service characteristics can be evaluated based on the travel speed and number of stops on the route [34]. Based on the travel demand data obtained in this study, the average travel speed (ATS) and number of stops (NOS) were employed as performance metrics of the route and service characteristics for each O-D pair with each travel mode.

The ATS is an important measure of performance and is determined by the following:

$$
A T S=\frac{T D}{T T}
$$

where $T D$ is the travel distance, and $T T$ is the travel time. In this study, the TD and TT were obtained from the program on the Baidu Map API. TD and TT were calculated for each $\mathrm{O}-\mathrm{D}$ pair for all travel modes. The time and distance required for the user to walk to his/her car, the time required for the user to wait for a taxi or public transit at the origin station, the time required for the user to park his/her car, and the distance traveled for parking were not considered in the calculation of the TT and TD.

NOS is the number of stops from the origin to the destination for each passenger traveling by $\mathrm{CB}$ or PT. For private cars, taxis, and bicycles, there are only two stops.

3.2.2. Service Reliability. Service reliability reflects the ability of a transit service to depart and arrive on time, which is a crucial aspect for users of public transit services [34]. The difference in arrival time is an index that can be used to describe the level of punctuality and reliability of a public transit service. Liu et al. [33] used the absolute value of the difference in the arrival time to compare the punctuality of different travel modes. However, whether they are arriving at their destination early or late makes a large difference for travelers, especially for commuters. Thus, in this study, the difference in arrival time $(D A T)$ is determined by the following:

$$
D A T=E A T-A A T
$$

where EAT is the expected arrival time and $A A T$ is the actual arrival time. The arrival time at the last station of each route, 
TABLE 1: Parameter values used to determine the monthly and daily travel expenses for CB services in Dalian.

\begin{tabular}{lccccccc}
\hline Parameter & $\alpha_{1}$ & $\alpha_{2}$ & $F_{2}$ & $F^{\prime}$ & $L_{0}$ & $L_{1}$ \\
\hline Monthly & 0.8 & 1 & 0 & $2 \mathrm{RMB}$ & $10 \mathrm{~km}$ & $5 \mathrm{~km}$ & $6 \mathrm{RMB}$ \\
Daily & 1 & 1 & 0 & $2 \mathrm{RMB}$ & $10 \mathrm{~km}$ & $5 \mathrm{~km}$ & $6 \mathrm{RMB}$ \\
\hline
\end{tabular}

which was available from the route information provided by the transit service provider, was taken as the EAT of the passengers. The $A A T$ was determined by adding the travel time estimated by an online map to the departure time for each passenger. The $A A T$ was also obtained by replanning the routes in the online map according to the departure time at the origin station for each $\mathrm{CB}$ route. A positive $D A T$ indicates that the passenger arrives at his/her destination earlier than the expected arrival time. Likewise, a negative DAT indicates that the passenger arrives at his/her destination later than the expected arrival time.

3.2.3. Travel Cost. The travel cost of a trip, including both money and time, is a major factor that significantly influences a passenger's choice of travel mode [37]. Thus, travel expense $(T E)$ and travel time $(T T)$ were defined as travel cost metrics in this study. For PT and taxis, the fares were obtained from the program on the online map. For private cars, the $T E$ was calculated based on the fuel cost and parking fees as follows:

$$
T E=\frac{C_{f} \times T D}{100} \times P_{f}+\left(T_{p} \times P_{p}\right)
$$

where $C_{f}$ is the average fuel consumption per $100 \mathrm{~km}$ for passenger vehicles; $P_{f}$ is the fuel price; $T_{p}$ is the total parking time, for which half of the total working hours (typically 8 h) were taken as the parking time per commute; and $P_{p}$ is the parking fee per hour. It was assumed in this study that all private cars used gasoline. The price of 95-octane gasoline was 7.2 RMB per liter in Dalian on December 14, 2017, according to Jintounet [38], where RMB is Renminbi, which is the official currency of the People's Republic of China. The average fuel consumption of passenger vehicles in China reached $6.9 \mathrm{~L}$ per $100 \mathrm{~km}$ in 2015 according to a report published by The Ministry of Industry and Information Technology of the People's Republic of China [39]. The parking fee in urban areas of Dalian was $5 \mathrm{RMB}$ per hour according to the Price Bureau of Dalian City [40]. Hence, the TE for private cars can be determined using Eq. (3).

The travel expense for passengers traveling by $\mathrm{CB}\left(T E_{C B}\right)$ was determined based on the distance tariff scheme [15] as follows:

$$
\begin{aligned}
T E_{C B} & =\alpha_{1} F_{1}+\alpha_{2} F_{2} \\
F_{1} & =\max \left\{0, F^{\prime}\left\lceil\frac{T D_{C B}-L_{0}}{L_{1}}\right\rceil\right\}+F_{0}
\end{aligned}
$$

where $F_{1}$ is the variable fare; $F_{2}$ is the constant fare; $\alpha_{1}$ and $\alpha_{2}$ are the discount factors for the variable fare and constant fare, respectively; $F^{\prime}$ is the fare factor for different travel distances; $L_{0}$ is the threshold travel distance; $L_{1}$ is the travel distance factor; $\lceil x\rceil$ is a function from which the smallest integer greater than or equal to $x$ can be acquired; and $F_{0}$ is the base fare for CB services.

The values of the parameters used to determine the monthly and daily travel expenses for CB services in Dalian are presented in Table 1 based on a previous study conducted by Liu and Ceder [15].

The metric regarding fuel consumption [33] is not included in this work. A part of running CBs in Dalian are electric vehicles and the actual energy consumption of electric vehicles is influenced by many environmental factors [41] such as interactive effects of ambient temperature and vehicle auxiliary loads [42] and road gradient [43]. The differences in the fuel/energy consumption estimations between internalcombustion engine bus and electric bus make it meaningless to be calculated and compared.

3.2.4. Data Collection. Based on the actual travel demand data, the routes for each $\mathrm{O}-\mathrm{D}$ in demand were replanned for these travel modes and the corresponding data were collected. These tasks were accomplished using the Baidu Map Application Programming Interface (API), which is a service provided by Baidu Inc. that enables developers to interact directly with the Baidu Map servers.

A person who commutes regularly by driving is assumed to be familiar with the routes that he/she has driven frequently. Thus, there is a high likelihood that the driver will choose the shortest-distance path to commute to/from work without using any navigational instruments in order to minimize fuel consumption. In contrast, taxi drivers are primarily concerned with travel time. Limited by the working hours per day, taxi drivers aim to minimize the travel time for each customer in order to increase turnover. Thus, taxi drivers always opt for the shortest-time route and the fare is charged from the passenger based on the taxi-tariff system in Dalian. For bicycling, there are few parts of roads designed with cycling paths and steep slopes can be seen on many roads. There are not many citizens who travel by bicycle until the prevalence of bike-sharing service. Thus sharing-bike is taken as an alternative in the transportation system of Dalian. For cyclists, the shortest path is the shortest-time route and the time-based tariff of the bike-sharing system prompts cyclists to choose the shortest-path [44]. The corresponding fare is collected according to the time-based tariff.

Because the CB transit mode was not available on the Baidu Map, CB routes were planned by running the program and setting the travel mode as "private car." In particular, minibuses are generally used in the $\mathrm{CB}$ and other demandresponsive transit systems [45] and present little difference in dynamic performance with private vehicle especially in the peak hours of the urban road network. The shortesttime route was chosen between every two contiguous stops of a route. Because $\mathrm{CB}$ drivers need to pick up and drop off 
TABLE 2: Means of performance metrics for the five travel modes (standard deviation in parentheses).

\begin{tabular}{|c|c|c|c|c|c|}
\hline & \multicolumn{5}{|c|}{ Performance metrics } \\
\hline & $T T(\min )$ & $\operatorname{ATS}(\mathrm{km} / \mathrm{h})$ & NOS & $D A T(\min )$ & TE (RMB) \\
\hline & \multicolumn{5}{|c|}{ Monthly subscriptions } \\
\hline \multirow[t]{2}{*}{ Bicycles } & 77 & 10.4 & - & - & 3 \\
\hline & (49) & $(0.01)$ & & & $(1.7)$ \\
\hline \multirow[t]{2}{*}{ CBs } & 52 & 22.69 & 7 & 7 & 8.9 \\
\hline & (31) & $(6.23)$ & $(3)$ & $(30)$ & (5.3) \\
\hline \multirow[t]{2}{*}{$\mathrm{PT}$} & 80 & 11.6 & 16 & -23 & 2.6 \\
\hline & $(27)$ & $(4.29)$ & (9) & $(26)$ & $(2.1)$ \\
\hline \multirow[t]{2}{*}{ Taxis } & 20 & 40.41 & - & - & 33 \\
\hline & (10) & $(6.61)$ & & & $(22.1)$ \\
\hline \multirow[t]{3}{*}{ Private cars } & 38 & 20.8 & - & - & 26.5 \\
\hline & $(16)$ & $(5.67)$ & & & $(4.0)$ \\
\hline & \multicolumn{5}{|c|}{ Daily subscriptions } \\
\hline \multirow[t]{2}{*}{ Bicycles } & 52 & 10.41 & - & - & 2.2 \\
\hline & (44) & $(0.01)$ & & & (1.4) \\
\hline \multirow[t]{2}{*}{ CBs } & 40 & 24.37 & 5 & 12 & 10.1 \\
\hline & $(36)$ & $(6.79)$ & (3) & (63) & $(5.2)$ \\
\hline \multirow[t]{2}{*}{ PT } & 54 & 10.4 & 13 & -2 & 1.3 \\
\hline & (31) & $(4.29)$ & (9) & $(58)$ & (1.7) \\
\hline \multirow[t]{2}{*}{ Taxis } & 14 & 35.72 & - & - & 23.6 \\
\hline & (10) & $(8.61)$ & & & $(16.7)$ \\
\hline \multirow[t]{2}{*}{ Private cars } & 26 & 23.44 & - & - & 24.4 \\
\hline & (21) & (6.14) & & & $(3.6)$ \\
\hline
\end{tabular}

passengers at appointed stops and appointed time, they often use navigational instruments throughout the trip to follow the shortest-time route.

For the PT data, the least-transfer-time route is select since PT shows obvious disadvantageous to other modes in terms of the transfer in the trip [33].

The program for the replanned CB routes was run on Thursday, November 30, 2017, based on the departure times at the origin stations for each CB. In particular, the departure times for each passenger at each pick-up/drop-off point on each route were obtained and used for other travel modes, which were calculated on Thursday, December 14, 2017. Thus, the travel information was derived at the same time of day and the same day of the week in order to minimize variations in the traffic scenarios between the different travel modes.

\section{Role of the CB System}

4.1. Performance Evaluations. A total of 72,496 monthly subscriptions and 38,486 daily subscriptions were replanned successfully by the program. The performance metrics (expressed in terms of the mean and standard deviation) are summarized in Table 2. Comparing the performance metrics for different travel modes reveals that traveling by taxi is more advantageous than other travel modes in terms of the $T T$ and ATS, but it is generally an expensive option. In contrast, bicycling is unfavorable in terms of the $T T$, and this travel mode is highly influenced by the weather conditions and topography of the area. Traveling by PT is advantageous because it is the cheapest mode of transportation, but it is also disadvantageous owing to its poor service quality (long travel times, low travel speeds, more stops on the bus routes, and a high possibility of delays). Traveling by private car provides the highest travel quality, but it is also an expensive option, for which parking fees play an important role. CB transit is more competitive than PT in terms of the TT, ATS, NOS, and $D A T$, but it is less advantageous in terms of the $T E$, compared with taxis and private cars.

In addition, as summarized in Table 3, the significance of the mean differences in the metrics between $\mathrm{CB}$ and $\mathrm{PT} /$ private car/taxi was evaluated using paired t-tests. The results indicate that although the TE is significantly increased, other metrics, including the TT, ATS, NOS, and DAT, are significantly improved for $\mathrm{CB}$ trips compared to PT. In fact, the cost of a trip by CB is still significantly far from that of a taxi (20.44 RMB) or private car (16.48 RMB).

The t-tests on the mean TT difference between $\mathrm{CB}$ versus $\mathrm{PT}$ and $\mathrm{CB}$ versus private cars further suggest that the timesaving achieved by shifting from PT to $\mathrm{CB}$ is significantly larger than that of shifting from $\mathrm{CB}$ to a private car. On the other hand, the cost increase incurred by shifting from PT to $\mathrm{CB}$ is significantly less than that of shifting from $\mathrm{CB}$ to private cars and taxis.

4.2. Advantages of Traveling by $C B$. In order to investigate the relationship among several performance metrics, a multinomial logit model is employed. Conventionally, multinomial logit models cannot be applied for samples such as ours, in 
TABLE 3: Results of paired mean difference t-tests.

\begin{tabular}{|c|c|c|c|c|}
\hline Variable & Mean & Std. dev. & $95 \% \mathrm{CI}$ & Sig. (2-tailed) \\
\hline$T T_{C B}-T T_{P T}$ & $-23.07 \mathrm{~min}$ & 28.28 & $-23.24--22.91$ & $<0.001$ \\
\hline$A T S_{C B}-A T S_{P T}$ & $12.09 \mathrm{~km} / \mathrm{h}$ & 6.13 & $12.05-12.12$ & $<0.001$ \\
\hline $\operatorname{NOS}_{C B}-\operatorname{NOS}_{P T}$ & -8.58 & 8.17 & $-8.63--8.53$ & $<0.001$ \\
\hline$D A T_{C B}-D A T_{P T}$ & $24.62 \mathrm{~min}$ & 30.41 & $24.43-24.81$ & $<0.001$ \\
\hline$T E_{C B}-T E_{C A R}$ & $-16.48 \mathrm{RMB}$ & 4.83 & $-16.50--16.45$ & $<0.001$ \\
\hline$T E_{C B}-T E_{T A X I}$ & $-20.44 \mathrm{RMB}$ & 18.53 & $-20.55--20.33$ & $<0.001$ \\
\hline$\left(T T_{P T}-T T_{C B}\right)-\left(T T_{C B}-T T_{C A R}\right)$ & $9.03 \mathrm{~min}$ & 50.11 & $8.74-9.32$ & $<0.001$ \\
\hline$\left(T E_{C B}-T E_{P T}\right)-\left(T E_{C A R}-T E_{C B}\right)$ & $-10.02 \mathrm{RMB}$ & 9.43 & $-10.08--9.96$ & $<0.001$ \\
\hline$\left(T E_{C B}-T E_{P T}\right)-\left(T E_{T A X I}-T E_{C B}\right)$ & $-12.03 \mathrm{RMB}$ & 17.48 & $-12.14--11.93$ & $<0.001$ \\
\hline
\end{tabular}

TABLE 4: Results of the multinomial logit model.

\begin{tabular}{lcccc}
\hline & Estimate & Std. Error & z-value & $-\operatorname{Pr}(>|z|)$ \\
\hline$T T$ & $-0.149 * *$ & 0.024 & -6.213 & -25.983 \\
TE & $-0.172 * *$ & 0.007 & 21.159 & $<0.001$ \\
ATS & $0.109 * *$ & 0.005 & -0.433 & 31.948 \\
NOS & -0.002 & 0.004 & -1.811 & 0.001 \\
DAT1 & $0.426 * *$ & 0.013 & 0.001 \\
DAT2 & -0.003 & 0.002 & \\
Log-Likelihood & -3186.3 & & \\
$\rho^{2}$ & 0.714 & & \\
$\mathrm{~N}$ & 6912 & & & \\
\hline
\end{tabular}

Note: ' $* *$ ' indicates that $\mathrm{p}<0.001$.

which all cases chose the same alternative (CB). However, the trade-off among variables such as the travel time and travel expense can be estimated by excluding alternative-specific constants from the model.

The alternatives are treated as unlabeled and only generic coefficients are included in the multinomial logit model. Unlabeled alternatives are often used for route choice analysis or stated preference survey where each alternative is represented only by the level of service attributes and no label is given to each alternative such as route 1 , route 2 , etc. Thus, it is not necessary to specify alternative-specific constants in the unlabeled model [46] and many software packages provide options of excluding alternative-specific constant MNL estimation, such as "mlogit" in R [47].

There are studies which indicate that the labeled or unlabeled treatment of alternative in the stated preference survey does not statistically affect the estimates of the coefficient parameters [48], and the unlabeled discrete choice experiment is more suitable to investigate trade-offs between attributes [49]. In our case, even though the treatment of the alternatives as unlabeled is not ideal since each mode may have alternative specific attributes to affect the mode choice, we believe it is still meaningful to investigate the relationship among several performance metrics by roughly treating the alternatives as unlabeled.

As discussed in Section 3.1, the monthly subscription retains a relatively stable number of passengers and contributes in large part to the successful operation of the CB system and therefore is focused in this chapter. In particular, all the 72,496 monthly orders were subscribed by 6,912 users, in total, during the research period (from Aug. 2015 to Sep. 2017). The metrics for each alternative (bicycles, CB, PT, taxis, and private cars) of these 6,912 O-Ds were obtained using the methods described in Section 3.2 and based on the replanning program on the online map.

All the five metrics were included in the model, in which alternative-specific constant terms were excluded. All of the metrics were assumed to have the same coefficients for the five modes. The estimation result of the model is summarized in Table 4. In the results for the variables in the multinomial model, the travel time, travel expense, and average travel speed are all significant and have the expected signs. The coefficient on NOS also has the expected sign but is insignificant. DAT1 indicates the positive DAT (arrival at the destination earlier than expected) while DAT2 indicates the negative DAT (arrival at the destination later than expected). The results show that arriving earlier is preferred to a later arrival.

The value of time from the model is $0.866 \mathrm{RMB}$ per 10 min. This means that if the travel time for a trip is reduced by $10 \mathrm{~min}$ (the unit of TT used in the model is $10 \mathrm{~min}$ ), the travel expense will be $0.866 \mathrm{RMB}$ greater to achieve the same utility. In other words, travelers are willing to pay $0.866 \mathrm{RMB}$ in order to save $10 \mathrm{~min}$ on their trips.

Based on the multinomial logit model calibrated, the probability of choosing the $\mathrm{CB}$ travel can be calculated for each individual. In particular, the probabilities in each zone are averaged and then multiplied by the population 

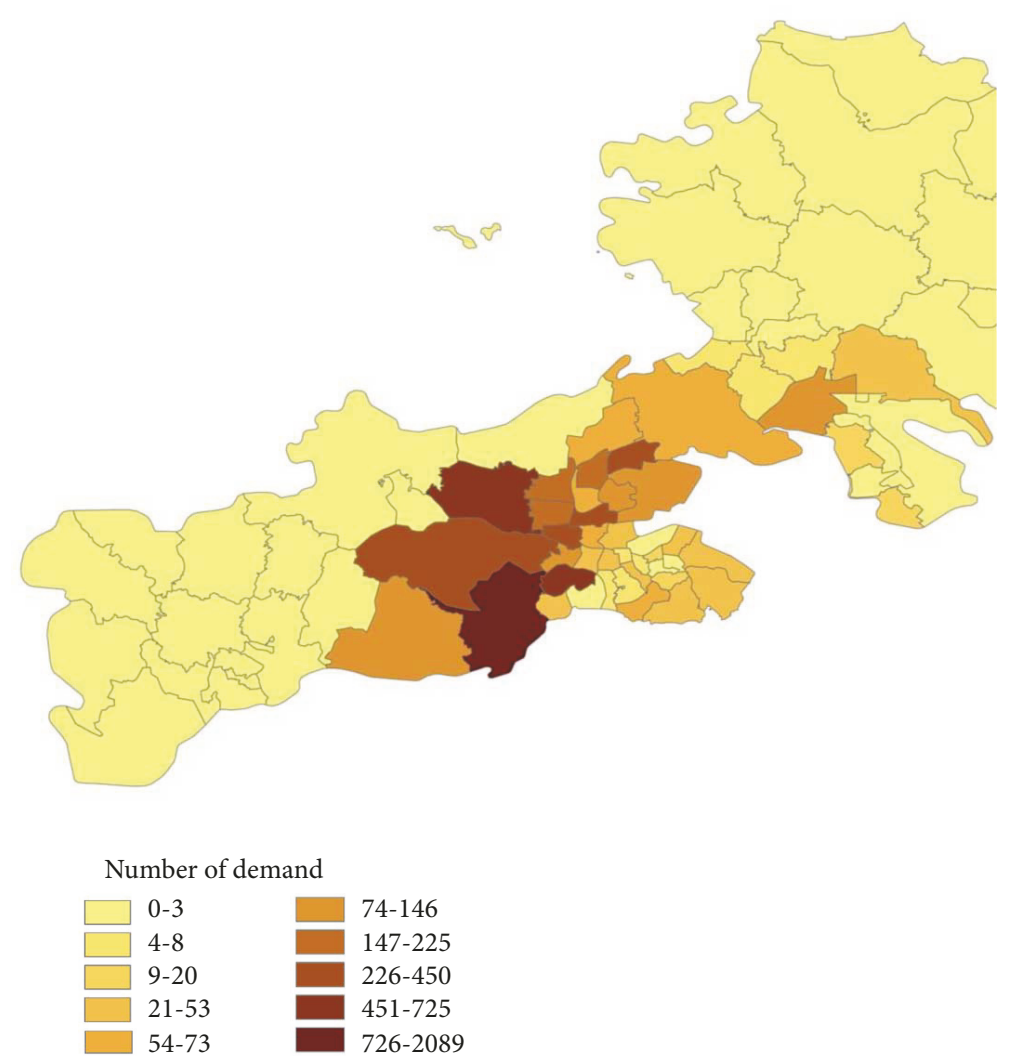

FIgURE 3: Distribution of the actual demand of the CB system on the township scale.

TABLE 5: Estimation results of the ordinary least squares regression and geographically weighted regression models.

\begin{tabular}{lccc}
\hline & & Ordinary least squares regression model \\
\hline Variable & Coefficient & Std. Err. & t-value \\
\hline Intercept & -27.5257 & 31.5135 & -0.8735 \\
Relative advantage & $0.0041 * *$ & 0.0007 & 5.8036 \\
$\mathrm{~N}$ & 80 & & \\
R-squared & 0.302 & \\
AICc & 1094 & Geographically weighted regression model \\
\hline & & & \\
\hline Bandwidth & 0.148 & \\
Sigma & 169.310 & \\
R-squared & 0.642 & \\
AICc & 1058 & & \\
\hline
\end{tabular}

Note: AICc denotes Akaike’s Information Criterion; ' $* *$ ' indicates that $\mathrm{p}<0.001$.

to indicate the advantages of traveling by $\mathrm{CB}$ (on the township level). The analysis of the relationship between the spatial distribution of the advantage and actual demand will help reveal the mechanism of the spatial distribution in demand. The population data is sourced from the population census of China conducted in 2010 on the township scale [50], which is the latest population census conducted in China.

Figure 3 shows the spatial distribution of the actual demand. Most of the demand is concentrated in the central area of Dalian, as shown by the darker-colored areas. There is no demand served in the most western and northern areas of the city.

Figure 4 illustrates the spatial distribution of the product of population and mean probability on the township scale, indicating the relative advantage of subscribing to a $\mathrm{CB}$ service on the zone level (township scale).

The relationship between the relative advantage of using a $\mathrm{CB}$ service and the actual demand is examined by regressing the actual demand with respect to the relative advantage. The results of the regression models are listed in Table 5. The results show a significant positive relationship between the 

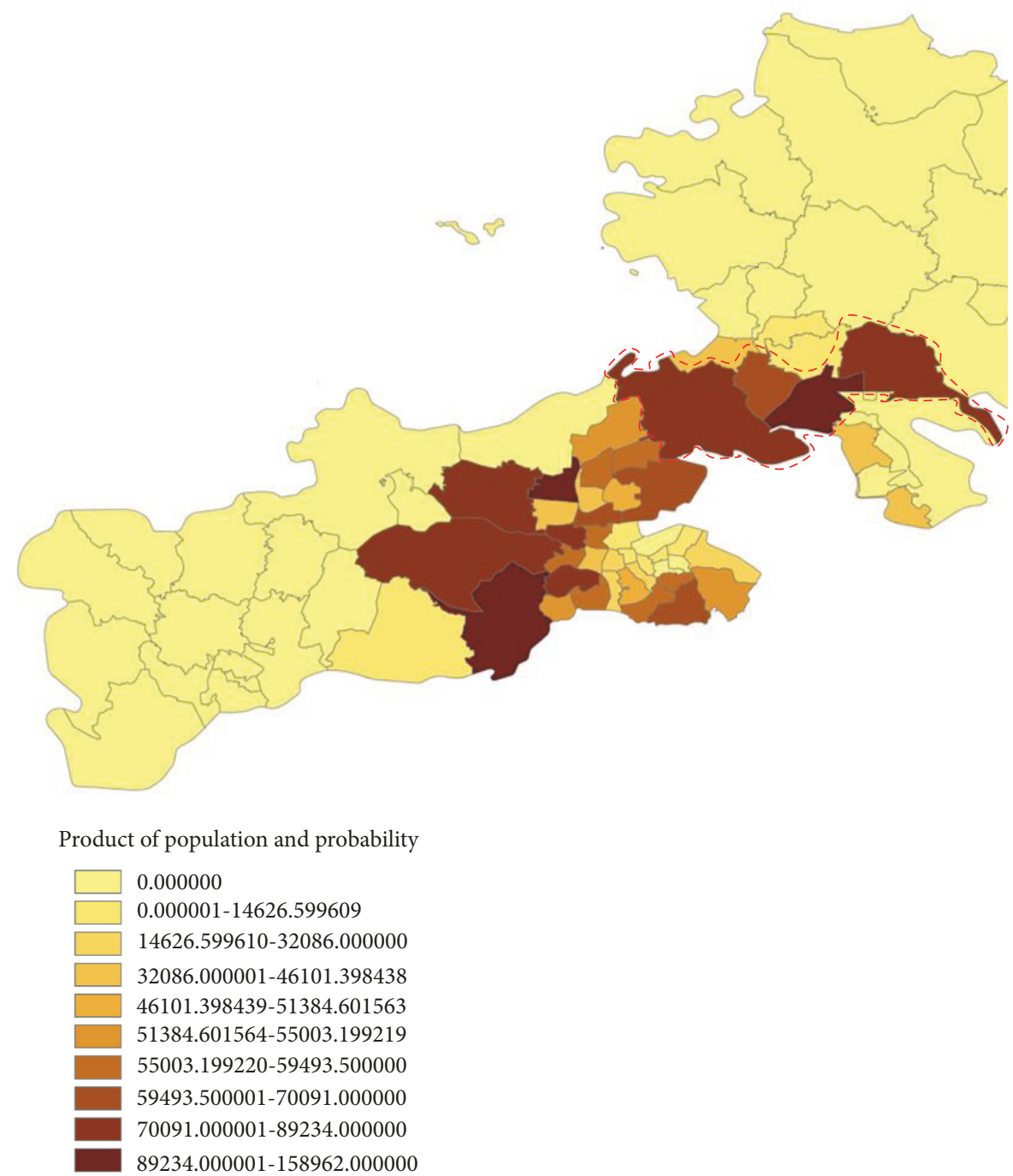

FIGURE 4: Distribution of the product of the population and mean probability on the township scale.

relative advantage and the demand. However, the residuals of the ordinary least squares model exhibit spatial clustering, indicating that the relationship between the explanatory variable and the dependent variable is spatially autocorrelated. After considering the spatial autocorrelation using a geographically weighted regression model [51], more than $64 \%$ of the variation in the demand can be explained by the relative advantage by zone.

Comparing Figures 3 and 4 reveals that most zones are covered with the same or similar colors, particularly the highdemand zones in central Dalian. Nevertheless, a big difference is shown in some areas in eastern Dalian, particularly in the zones surrounded by the red dotted line in Figure 4. It is a newly developed city subcenter and with an increasing population collected in eastern Dalian. From the distribution of population illustrated in Figure 5, we can see the great number of residents collected in these areas which naturally lead to a larger amount of demand to use CB service. The advantages of traveling by $\mathrm{CB}$ in these areas (surrounded by the red dotted line) show consistent higher values among areas of eastern Dalian.

The destinations of the demand in these areas are concentrated in the several zones where the city centers are located in the central Dalian, as illustrated in Figure 6. However, the $\mathrm{CB}$ demand flows from these areas, obviously, experience longer distances than the demand in the central Dalian. Undoubtedly, the bus sharing system is facing more challenges with long-distance routes, as it would have more difficulties in finding enough partners due to the small number of trips from the same origin zone to the same destination zone with similar departure/arrival times requested [52] and make the demand-responsive transit service unreliable [27]. It is not strange that only a few routes were successfully launched to serve demand from these areas to the central Dalian, therefore, leading to the big difference between the theoretically estimated and the actual demand. On the other hand, the difference suggests a marketing potential for a more flexible and complicated route design of CB service, for 


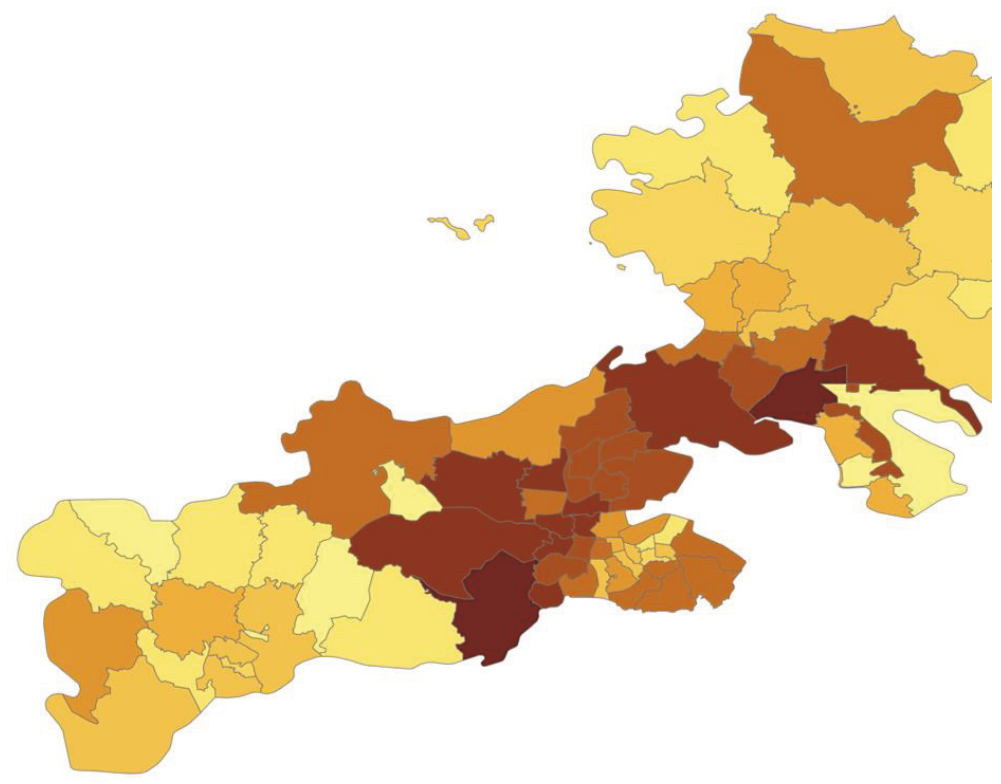

Population
$0-7166$
7167-20477
41610-52118
20478-28057
52119-64370
28058-34046
64371-86012
34047-41609
86013-125548
$125549-190135$

FIGURE 5: Distribution of population on the township scale.

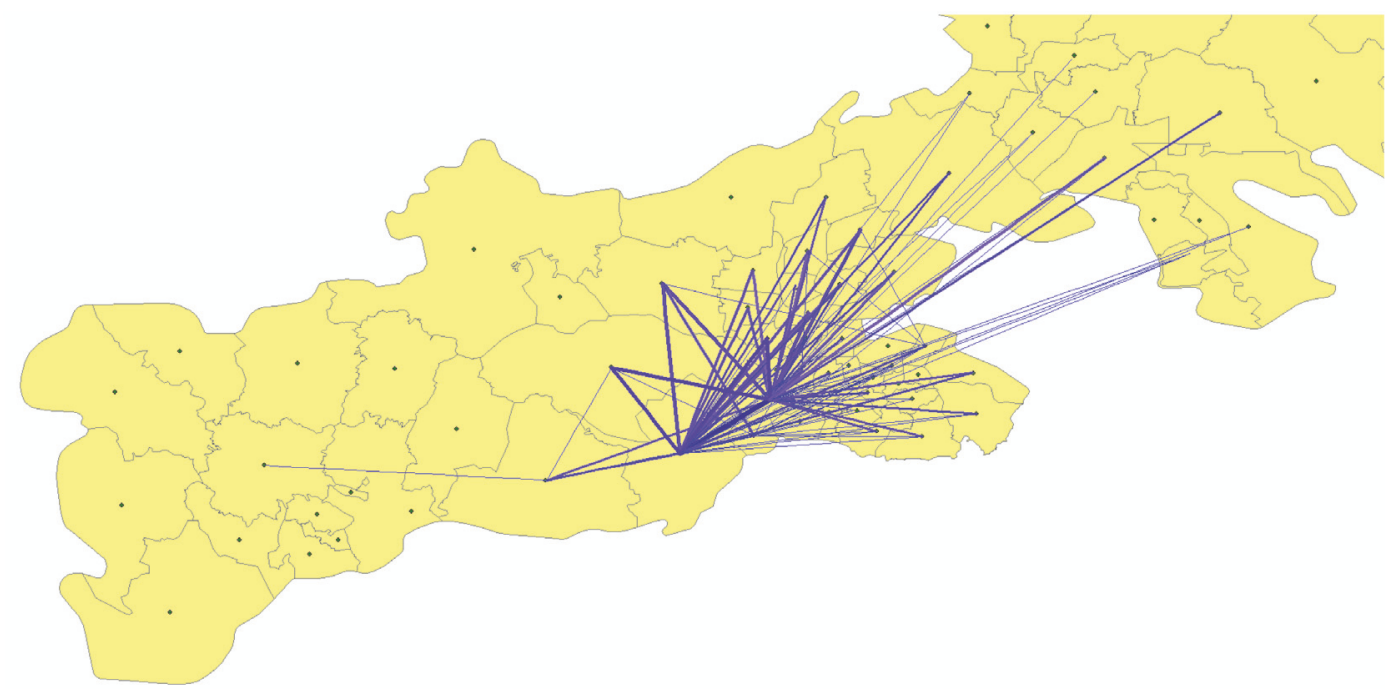

Demand flow of $\mathrm{CB}$

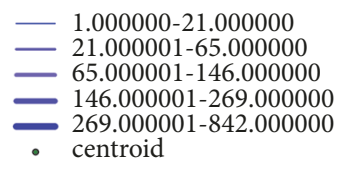

Figure 6: Desire line of CB demand. 


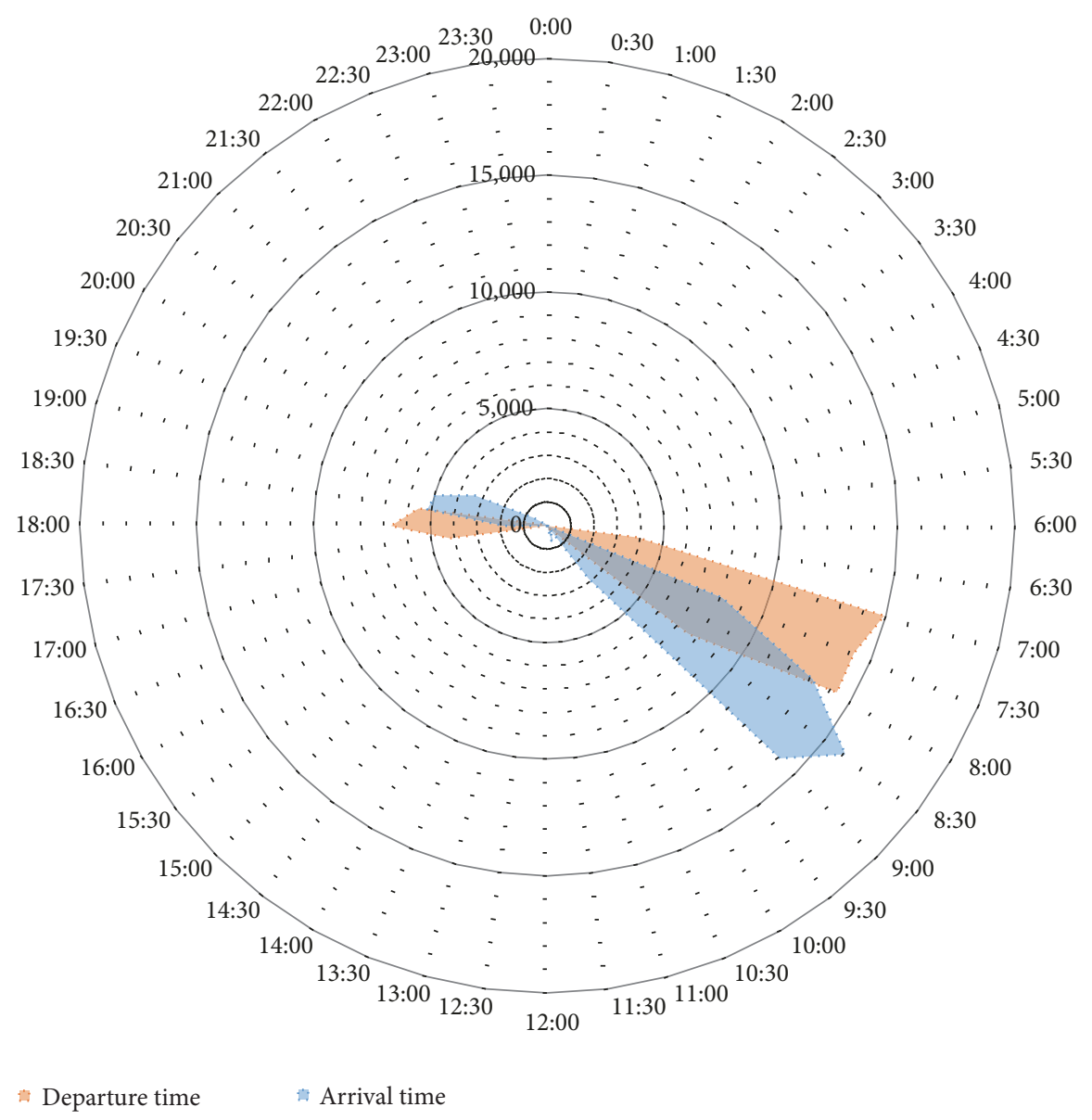

FIGURE 7: Distribution of the departure and arrival times for monthly subscriptions.

instance, once-transfer-permitted route design, especially for long-distance travels.

4.3. Spatial and Temporal Coverage. Based on the demand from online surveys, the pick-up and drop-off stations for each route are relatively concentrated. The departure time and arrival time of each passenger dispatched in a single bus are scheduled to be as similar as possible. The temporal coverage of monthly CB subscriptions is illustrated in Figure 7. The results show that the departure times of the demand are concentrated from 07:00 to 08:00 in the morning and from 17:30 to 18:30 in the afternoon. The arrival times are concentrated from 08:00 to 09:00 in the morning and from 18:30 to 19:30 in the afternoon. As a result, the time period during travel falls exactly in the rush period of the road network in Dalian. Thus, the reductions in travel time for passengers who shift from $\mathrm{PT}$ to $\mathrm{CB}$ and in traffic load by attracting private car drivers to $\mathrm{CB}$ contribute to the improvement of traffic conditions, especially during peak hours.

To investigate the spatial coverage of the $\mathrm{CB}$ service and its relationship to PT services, the number of PT stations around each $\mathrm{CB}$ demand point is counted. In particular, information on the PT stations in the whole city area, including bus, subway, and rapid railway stations, was collected by mining the points of interest in Gaode Map on May 4th,

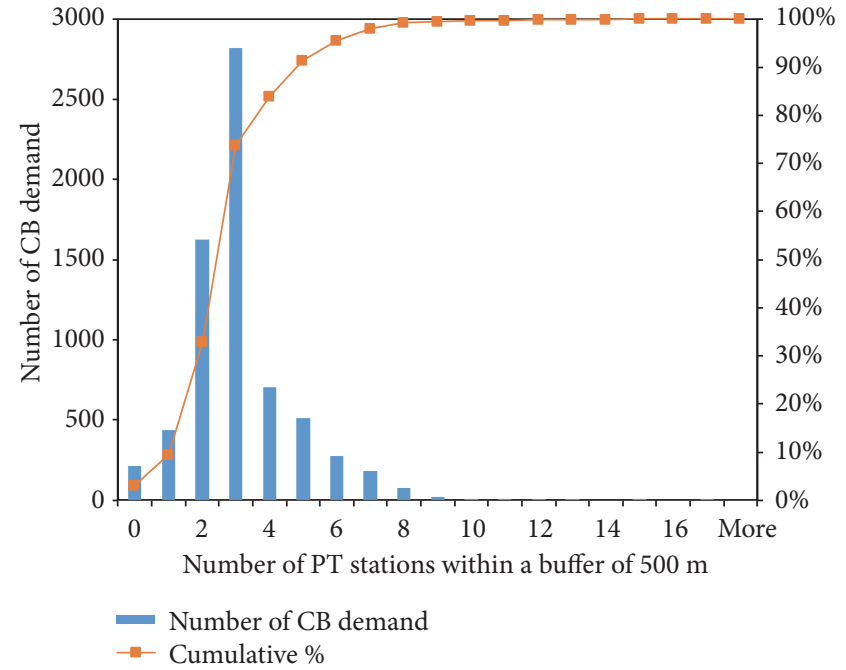

FIGURE 8: Number of PT stations within $500 \mathrm{~m}$ of each CB demand point.

2018. The resulting data mainly includes the coordinates for each station. The number of PT stations was counted within a buffer of $500 \mathrm{~m}$ for each $\mathrm{CB}$ demand point. The results are illustrated in Figure 8. For 6,912 demand points (for the 
monthly subscribers), more than 3\% (i.e., more than 200 users) are located in areas without any PT stations within $500 \mathrm{~m}$. In these cases, the CB system provides an extra mode choice and serves as the main bus transit service. In more than $73 \%$ of the cases, the number of PT stations within $500 \mathrm{~m}$ is less than four, suggesting that the $\mathrm{CB}$ service primarily acts to supplement the PT service in areas with poor coverage levels.

\section{Conclusions}

After failures were experienced in the development of CB systems in some cities, the feasibility of this new bus sharing system is being questioned. Blindly developing a CB system before being perfectly clear regarding its role in the overall transportation realm can lead to a huge waste of resources in those cities that experience a drastic decline in customers. Even though these systems have been developed for several years, there is still no consensus on their role. Thus, it is imperative to investigate the actual role of $\mathrm{CB}$ services in the overall transportation realm based on successful cases, as the role of the $\mathrm{CB}$ service determines its primary service object, system construction, marketing orientation, and even government function.

For this purpose, the present study investigates the practical performance, advantages, and spatial and temporal coverage of a CB system based on actual subscription data collected over more than two years to cover this gap.

Comparison of performance metrics for all available transportation modes shows that while the $T E$ increased, the $\mathrm{CB}$ service significantly improved the travel experience in terms of the travel time, travel speed, number of stations, and difference arrival time compared to traditional PT services. The results of the t-test indicate that, with a relatively small increase in travel cost, significant time savings can be achieved by shifting from $\mathrm{PT}$ to $\mathrm{CB}$, compared to the $T T$ differences between $\mathrm{CB}$ and a private car/taxi. On the other hand, a private car only provides a small advantage in travel time over CBs, but it increases the cost significantly. This indicates that the $\mathrm{CB}$ service is an eclectic choice to balance service quality and cost.

Most of the metrics selected in this study exhibit the expected signs and significance in the discrete choice model. The results of the geographically weighted regression model demonstrated a significant positive relationship between the relative advantage and the amount of demand. Based on the differences in the distributions of the estimated advantages and actual demand, it can be concluded that the longdistance routes increase more challenges in finding enough passengers with similar O-Ds and departure/arrival times and therefore leading to the big difference between the theoretically estimated and the actual demand. Moreover, the big difference suggests a marketing potential for a more flexible and complicated $\mathrm{CB}$ service design such as oncetransfer-permitted route design, especially for long-distance travels.

Investigation of the temporal coverage reveals that the time period of peak travel with the $\mathrm{CB}$ service falls exactly in the rush period of the road network in Dalian. Thus, the reductions in travel time for passengers who shift from
PT to $\mathrm{CB}$ and in traffic load achieved by attracting private car drivers are contributing to an improvement in traffic conditions, especially during peak hours. Investigation of the spatial coverage indicates that the $\mathrm{CB}$ service mainly acts to supplement traditional PT services in areas with poor coverage levels, while it serves as the main bus transit service in several areas without PT service (within $500 \mathrm{~m}$ ).

\section{Data Availability}

The raw data used to support the findings of this study have not been made available because of privacy issue.

\section{Conflicts of Interest}

The authors declare that they have no conflicts of interest.

\section{Acknowledgments}

The first author graciously acknowledges the China Scholarship Council (CSC) for their financial support. This work was carried out by the joint research program of the Institute of Materials and Systems for Sustainability, Nagoya University. The last author would like to acknowledge support funding from the National Natural Science Foundation of China (Grant No. 51378091 and No. 71871043), the National Natural Science Foundation of Liaoning Province, China (Grant No. 20170540187), and the Fundamental Research Funds for the Central Universities of China (Grant No. DUT18GJ204).

\section{References}

[1] Ministry of Public Security of the People's Republic of China, "The highly increased car ownership and drivers in China," 2018, http://www.mps.gov.cn/n2254098/n4904352/c5976651/ content.html.

[2] J. Pucher, Z. Peng, N. Mittal, Y. Zhu, and N. Korattyswaroopam, "Urban transport trends and policies in china and india: impacts of rapid economic growth," Transport Reviews, vol. 27, no. 4, pp. 379-410, 2007.

[3] L. Zhang, R. Long, H. Chen, and T. Yang, "Analysis of an optimal public transport structure under a carbon emission constraint: a case study in Shanghai, China," Environmental Science and Pollution Research, vol. 25, no. 4, pp. 3348-3359, 2018.

[4] L. Chapman, “Transport and climate change: a review," Journal of Transport Geography, vol. 15, pp. 354-367, 2007.

[5] J. Q. Li, "Battery-electric transit bus developments and operations: A review," International Journal of Sustainable Transportation, vol. 10, Article ID 872737, pp. 157-169, 2016.

[6] X. Wang and J. A. González, "Assessing feasibility of electric buses in small and medium-sized communities," International Journal of Sustainable Transportation, vol. 7, no. 6, pp. 431-448, 2013.

[7] D. L. Greene and M. Wegener, "Sustainable transport," Journal of Transport Geography, vol. 5, pp. 177-190, 1997.

[8] R. Zhong, J. Sun, and Q. Lu, "China's public transportation: problems, policies, and prospective of sustainability," ITE Journal, vol. 82, no. 5, pp. 36-40, 2012.

[9] S. Harms and B. Truffer, The emergence of a nation-wide carsharing co-operative in Switzerland, Holland, 1998. 
[10] S. A. Shaheen and A. P. Cohen, "Growth in worldwide carsharing: an international comparison," Transportation Research Record, vol. 1992, no. 1, pp. 81-89, 2007.

[11] R. F. Kirby and K. U. Bhatt, Guidelines on The Operation of Subscription Bus Services, Wash, DC., USA, 1974.

[12] D. A. Morin, "Commuter bus clubs are showing the "professionals" how to meet transit demand," Traffic Engineering - Institute of Transportation Engineers, vol. 44, pp. 24-27, 1974.

[13] J. A. Bautz, "Subscription service in the United States," Transportation, vol. 4, no. 4, pp. 387-402, 1975.

[14] R. F. Kirby and K. U. Bhatt, "An analysis of subscription bus experience," Traffic Quarterly, vol. 29, no. 3, pp. 403-425, 1975.

[15] T. Liu and A. Ceder, "Analysis of a new public-transport-service concept: customized bus in China," Transport Policy, vol. 39, pp. 63-76, 2015.

[16] J. Brake, J. D. Nelson, and S. Wright, "Demand responsive transport: towards the emergence of a new market segment," Journal of Transport Geography, vol. 12, no. 4, pp. 323-337, 2004.

[17] C. Mulley and J. D. Nelson, "Flexible transport services: A new market opportunity for public transport," Research in Transportation Economics, vol. 25, no. 1, pp. 39-45, 2009.

[18] P. Bearse, S. Gurmu, C. Rapaport, and S. Stern, "Paratransit demand of disabled people," Transportation Research Part B: Methodological, vol. 38, no. 9, pp. 809-831, 2004.

[19] X. Ma, Y. J. Wu, Y. Wang, F. Chen, and J. Liu, "Mining smart card data for transit riders' travel patterns," Transportation Research Part C: Emerging Technologies, vol. 36, pp. 1-12, 2013.

[20] J. Ma, Y. Zhao, Y. Yang et al., "A model for the stop planning and timetables of customized buses," PLOS ONE, vol. 12, no. 1, Article ID e0168762, pp. 1-28, 2017.

[21] A. Perugia, L. Moccia, J. Cordeau, and G. Laporte, "Designing a home-to-work bus service in a metropolitan area," Transportation Research Part B: Methodological, vol. 45, no. 10, pp. 17101726, 2011.

[22] G. C. Clarens and V. F. Hurdle, "An operating strategy for a commuter bus system," Transportation Science, 1975.

[23] M. Amirgholy and E. J. Gonzales, "Demand responsive transit systems with time-dependent demand: user equilibrium, system optimum, and management strategy," Transportation Research Part B: Methodological, vol. 92, pp. 234-252, 2016.

[24] G. Solvoll and T. S. Hanssen, "User satisfaction with specialised transport for disabled in Norway," Journal of Transport Geography, vol. 62, pp. 1-7, 2017.

[25] L. Davison, M. Enoch, T. Ryley, M. Quddus, and C. Wang, "A survey of demand responsive transport in great Britain," Transport Policy, vol. 31, pp. 47-54, 2014.

[26] C. Sun, X. Chen, H. M. Zhang, and Z. Huang, "An evaluation method of urban public transport facilities resource supply based on accessibility," Journal of Advanced Transportation, vol. 2018, pp. 1-11, 2018.

[27] J. Mageean and J. D. Nelson, "The evaluation of demand responsive transport services in Europe," Journal of Transport Geography, vol. 11, no. 4, pp. 255-270, 2003.

[28] L. Zou, H. Dai, E. Yao, T. Jiang, and H. Guo, "Research on assessment methods for urban public transport development in China," Computational Intelligence and Neuroscience, vol. 2014, Article ID 941347, 8 pages, 2014.

[29] J. Li, X. Chen, X. Li, and X. Guo, "Evaluation of public transportation operation based on data envelopment analysis," Procedia - Social and Behavioral Sciences, vol. 96, pp. 148-155, 2013.
[30] L. Redman, M. Friman, T. Gärling, and T. Hartig, "Quality attributes of public transport that attract car users: A research review," Transport Policy, vol. 25, pp. 119-127, 2013.

[31] R. de Oña, J. de Abreu e Silva, C. Muñoz-Monge, and J. de Oña, "Users' satisfaction evolution of a metropolitan transit system in a context of economic downturn," International Journal of Sustainable Transportation, vol. 12, no. 1, pp. 66-74, 2018.

[32] L. Dell'Olio, A. Ibeas, and P. Cecin, "The quality of service desired by public transport users," Transport Policy, vol. 18, no. 1, pp. 217-227, 2011.

[33] T. Liu, A. A. Ceder, and R. Bologna, "Commuting by customized bus: a comparative analysis with private car and conventional public transport in two cities," Journal of Public Transportation, vol. 19, no. 2, pp. 55-74, 2016.

[34] L. Eboli and G. Mazzulla, "A methodology for evaluating transit service quality based on subjective and objective measures from the passenger's point of view," Transport Policy, vol. 18, no. 1, pp. 172-181, 2011.

[35] National Bureau of Statistics of the People's Republic of China, "Tabulation on the 2010 Population Census of the People's Republic of China," 2011, http://www.stats.gov.cn/tjsj/pcsj/ rkpc/6rp/indexch.htm.

[36] Dalian Municipal Bureau of Statistics, "Dalian Statistic Yearbook," 2017, http://www.stats.dl.gov.cn/index.php?m=content\& $\mathrm{c}=$ index\&a $=$ lists\&catid $=57$.

[37] S. Chowdhury, A. Ceder, and B. Schwalger, "The effects of travel time and cost savings on commuters' decision to travel on public transport routes involving transfers," Journal of Transport Geography, vol. 43, pp. 151-159, 2015.

[38] Jintounet, "Real Time Gasoline Price Inquiry," 2017, http://www .cngold.org/c/2017-12-14/c5541781.html.

[39] Ministry of Industry and Information Technology of the People's Republic of China, "Interpretation of the fourth stage standard of passenger car fuel consumption," 2015, http://www .miit.gov.cn/n1146285/n1146352/n3054355/n3057585/n3057589/ c3616982/content.html.

[40] Price Bureau of Dalian City, "Notice on Printing and Distributing Charging Standard of Motorized Parking Service," 2014, http://www.wjj.dl.gov.cn/htmlfile/3/21557.html?xyz= 0.3004350671436528 .

[41] J. Wang, K. Liu, and T. Yamamoto, "Improving electricity consumption estimation for electric vehicles based on sparse GPS observations," Energies, vol. 10, no. 1, article no 129, 2017.

[42] K. Liu, J. Wang, T. Yamamoto, and T. Morikawa, "Exploring the interactive effects of ambient temperature and vehicle auxiliary loads on electric vehicle energy consumption," Applied Energy, vol. 227, pp. 324-331, 2018.

[43] K. Liu, T. Yamamoto, and T. Morikawa, "Impact of road gradient on energy consumption of electric vehicles," Transportation Research Part D: Transport and Environment, vol. 54, pp. 74-81, 2017.

[44] J. R. Lin, T. H. Yang, and Y. C. Chang, "A hub location inventory model for bicycle sharing system design: Formulation and solution," Journal of Industrial Engineering, vol. 65, no. 1, pp. 7786, 2013.

[45] J. D. Nelson, S. Wright, B. Masson, G. Ambrosino, and A. Naniopoulos, "Recent developments in flexible transport services," Research in Transportation Economics, vol. 29, no. 1, pp. 243248, 2010.

[46] M. Sarrias and R. Daziano, "Multinomial logit models with continuous and discrete individual heterogeneity in $\mathrm{R}$ : The gmnl Package," Journal of Statistical Software, vol. 79, no. 2, 2017. 
[47] Y. Croissant, "Estimation of multinomial logit models in R: The mlogit Packages," 2011, https://pdfs.semanticscholar.org/8d40/ 143d338c298a4b5e6d421a730d54908c9eba.pdf.

[48] W. Jin, H. Jiang, Y. Liu, E. Klampfl, and X. Ma, "Do labeled versus unlabeled treatments of alternatives' names influence stated choice outputs? Results from a mode choice study," PLoS ONE, vol. 12, no. 8, pp. 1-24, 2017.

[49] E. W. de Bekker-Grob, L. Hol, B. Donkers et al., "Labeled versus unlabeled discrete choice experiments in health economics: an application to colorectal cancer screening," Value in Health, vol. 13, no. 2, pp. 315-323, 2010.

[50] N. Feng, Tabulation on the population census of the people's republic of China by township, China statistics press, Beijing, China, 2012.

[51] C. Brunsdon, A. S. Fotheringham, and M. E. Charlton, "Geographically weighted regression: a method for exploring spatial nonstationarity," Geographical Analysis, vol. 28, no. 4, pp. 281298, 1996.

[52] G. Correia and J. M. Viegas, "A conceptual model for carpooling systems simulation," Journal of Simulation, vol. 3, no. 1, pp. 6168, 2009. 


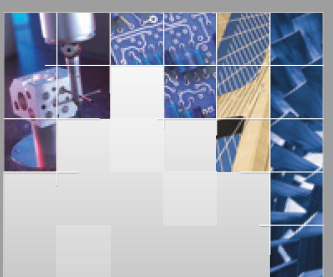

\section{Enfincering}
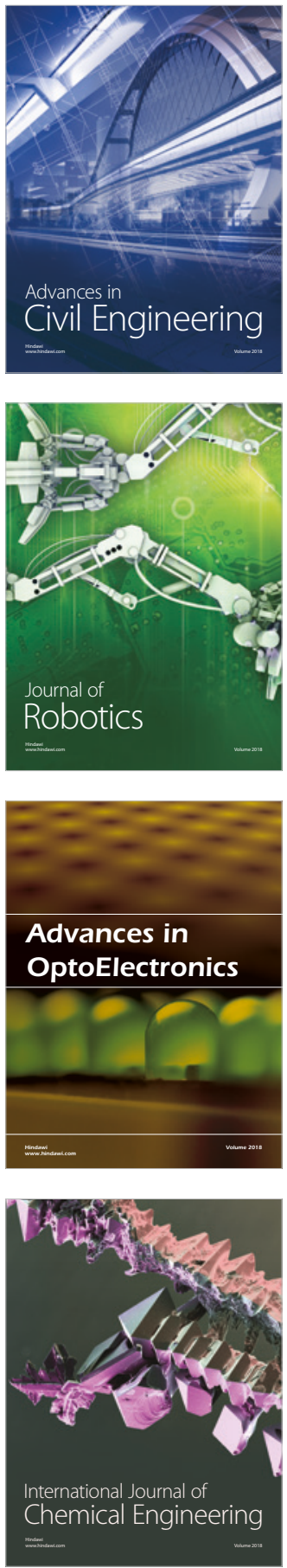

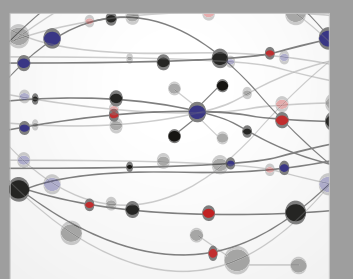

\section{Rotating \\ Machinery}

The Scientific World Journal

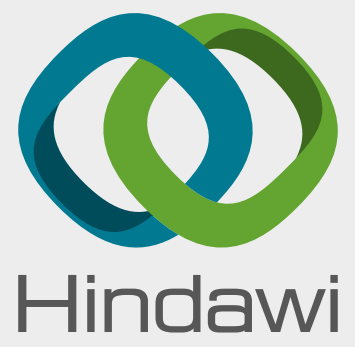

Submit your manuscripts at

www.hindawi.com
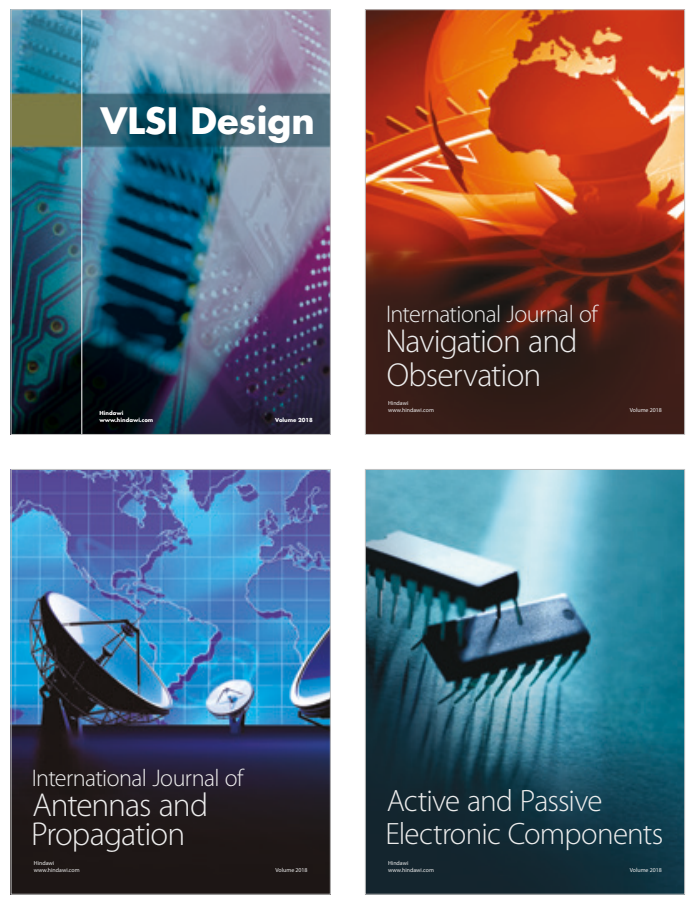
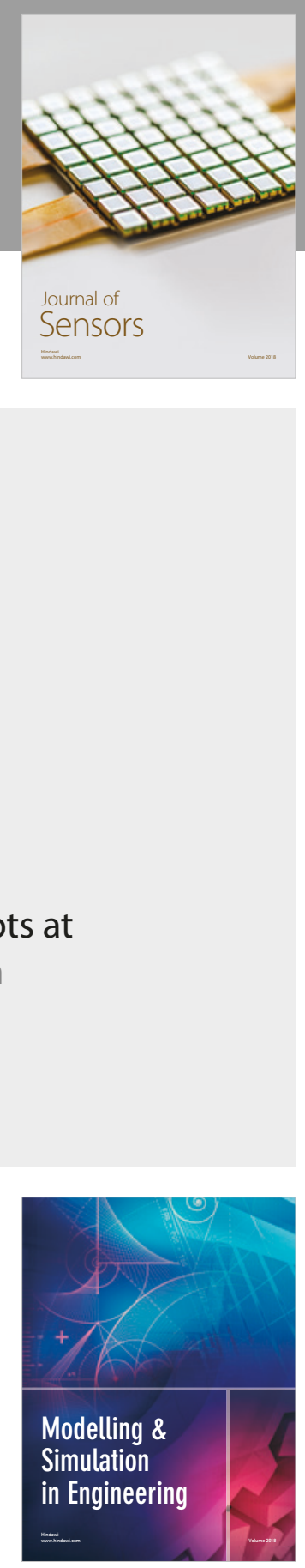

\section{Advances \\ Multimedia}
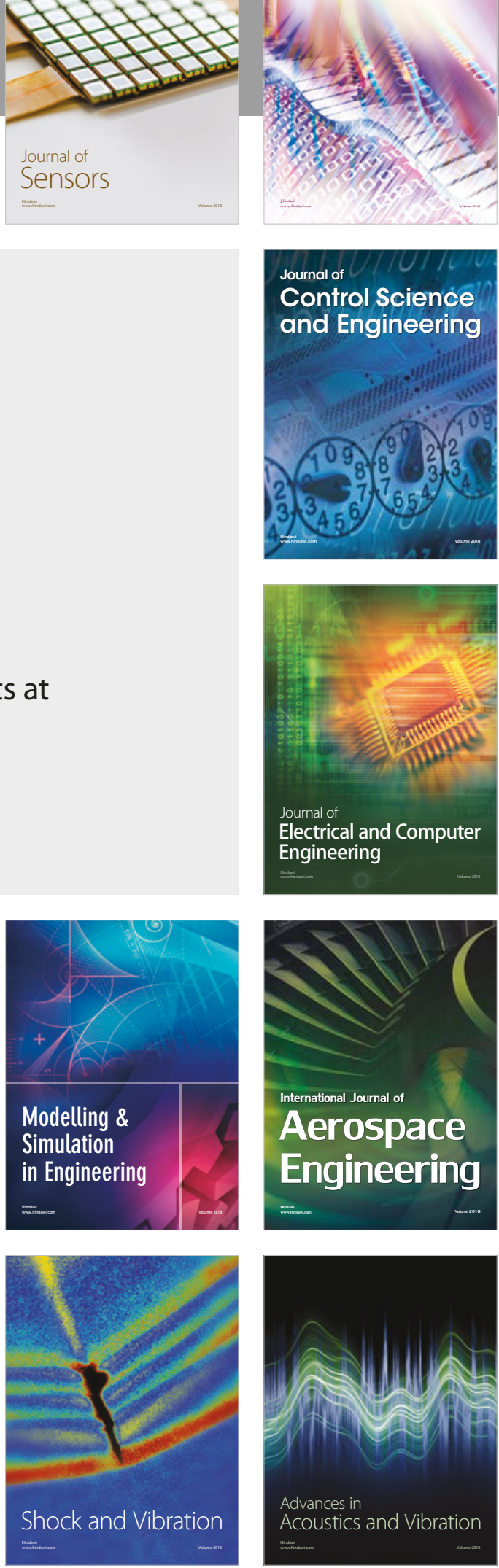